University of Nebraska - Lincoln

DigitalCommons@University of Nebraska - Lincoln

3-14-1997

\title{
Characterization of Recombinant Soybean Leghemoglobin $a$ and Apolar Distal Histidine Mutants
}

\author{
Mark S. Hargrove \\ Rice University, Houston, TX \\ Jennifer K. Barry \\ Rice University, Houston, TX \\ Eric Allen Brucker \\ Rice University, Houston, TX \\ Michael B. Berry \\ Rice University, Houston, TX \\ George N. Phillips, Jr. \\ Rice University, Houston, TX \\ See next page for additional authors
}

Follow this and additional works at: https://digitalcommons.unl.edu/biochemistrysarath

Part of the Biochemistry, Biophysics, and Structural Biology Commons

Hargrove, Mark S.; Barry, Jennifer K.; Brucker, Eric Allen; Berry, Michael B.; Phillips, Jr., George N.; Olson, John S.; Arredondo-Peter, Raúl; Dean, Jeanenne M.; Klucas, Robert V.; and Sarath, Gautam, "Characterization of Recombinant Soybean Leghemoglobin a and Apolar Distal Histidine Mutants" (1997). Gautam Sarath Publications. 20.

https://digitalcommons.unl.edu/biochemistrysarath/20

This Article is brought to you for free and open access by the Biochemistry, Department of at DigitalCommons@University of Nebraska - Lincoln. It has been accepted for inclusion in Gautam Sarath Publications by an authorized administrator of DigitalCommons@University of Nebraska - Lincoln. 


\section{Authors}

Mark S. Hargrove; Jennifer K. Barry; Eric Allen Brucker; Michael B. Berry; George N. Phillips, Jr.; John S. Olson; Raúl Arredondo-Peter; Jeanenne M. Dean; Robert V. Klucas; and Gautam Sarath 


\title{
Characterization of recombinant soybean leghemoglobin a and apolar distal histidine mutants
}

\author{
Mark S. Hargrove, ${ }^{1}$ Jennifer K. Barry, ${ }^{1}$ Eric Allen Brucker, ${ }^{1}$ Michael B. Berry, ${ }^{1}$ \\ George N. Phillips, Jr., ${ }^{1}$ John S. Olson, ${ }^{1}$ Raúl Arredondo-Peter, ${ }^{2}$ Jeanenne M. Dean, ${ }^{2}$ \\ Robert V. Klucas, ${ }^{2}$ and Gautam Sarath ${ }^{2}$ \\ ${ }^{1}$ Department of Biochemistry and Cell Biology, Rice University, Houston, TX 77005-1892, USA \\ 2 Department of Biochemistry, University of Nebraska-Lincoln, Lincoln, NE 68588-0664, USA \\ ${ }^{*}$ Corresponding author - M. S. Hargrove
}

\begin{abstract}
The cDNA for soybean leghemoglobin a (Lba) was cloned from a root nodule cDNA library and expressed in Escherichia coli. The crystal. structure of the ferric acetate complex of recombinant wild-type Lba was determined at a resolution of $2.2 \AA$. Rate constants for $\mathrm{O}_{2}, \mathrm{CO}$ and NO binding to recombinant Lba are identical. with those of native soybean Lba. Rate constants for hemin dissociation and auto-oxidation of wild-type Lba were compared with those of sperm whale myoglobin. At $37^{\circ} \mathrm{C}$ and $\mathrm{pH} 7$, soybean $\mathrm{Lba}$ is much less stable than sperm whale myoglobin due both to a fourfold higher rate of auto-oxidation and to a $~ 600$-fold lower affinity for hemin. The role of His61(E7) in regulating oxygen binding was examined by site-directed mutagenesis. Replacement of His(E7) with Ala, Val. or Leu causes little change in the equilibrium constant for $\mathrm{O}_{2}$ binding to soybean Lba, whereas the same mutations in sperm whale myoglobin cause 50 to 100 -fold decreases in $K_{\mathrm{O}_{2}}$. These results show that, at neutral. $\mathrm{pH}$, hydrogen bonding with $\mathrm{His}(\mathrm{E} 7)$ is much less important in regulating $\mathrm{O}_{2}$ binding to the soybean protein. The His(E7) to Phe mutation does cause a significant decrease in $\mathrm{K}_{\mathrm{O}_{2}}$ for $\mathrm{Lba}$, apparently due to steric hindrance of the bound ligand. The rate constants for $\mathrm{O}_{2}$ dissociation from wild-type and native $\mathrm{Lba}$ decrease significantly with decreasing $\mathrm{pH}$. In contrast, the $\mathrm{O}_{2}$ dissociation rate constants for mutants with apolar E7 residues are independent of $\mathrm{pH}$, suggesting that hydrogen bonding to the distal. histidine residue in the native protein is enhanced under acid conditions. All of these results support the hypothesis that the high affinity of Lba for oxygen and other ligands is determined primarily by enhanced accessibility and reactivity of the heme group.
\end{abstract}

Keywords: soybean leghemoglobin, ligand binding, site-directed mutagenesis

Abbreviations: Lb, leghemoglobin; EPR, electron paramagnetic resonance; Mb, myoglobin

\section{Introduction}

Leghemoglobins $(\mathrm{Lb})$ are small monomeric heme proteins found in root nodules of leguminous plants. These proteins have unusually high affinities for oxygen compared to vertebrate myoglobins and hemoglobins. The association rate constants for $\mathrm{O}_{2}$ binding are very large $\left(1 \times 10^{8}\right.$ to $\left.3 \times 10^{8} \mathrm{M}^{-1} \mathrm{~s}^{-1}\right)$, whereas the dissociation rate constants are in the "normal" range for hemoglobins (5 to $30 \mathrm{~s}^{-1}$; Gibson et al. 1989). High oxygen affinity is required to prevent inhibition of nitrogen fixation, and a moderate dissociation rate constant is necessary for fa- cilitating diffusion of oxygen to a high-affinity bacteroid oxidase (Appleby 1992).

The tertiary folding patterns of lupin and soybean $\mathrm{Lb}$ are very similar to those of mammalian myoglobins, and the $\alpha$ and $\beta$ subunits of human hemoglobin. This pattern consists of seven a-helices $(\mathrm{A}$ to $\mathrm{H}$, minus the $\mathrm{D}$ helix found in most mammalian myoglobins) wrapped around an iron-protoporphyrin IX prosthetic group that is coordinated to the histidine side-chain of the eighth residue in the $\mathrm{F}$ helix. Leghemoglobins also contain a "distal" histidine residue at position E7. Polar interactions involving His-(E7) in mammalian myoglobins 
have been shown to play a key role in regulating ligand binding (Springer et al. 1994). The evidence for hydrogen bonding between bound $\mathrm{O}_{2}$ and the distal. histidine residue in leghemoglobin is less clear.

Comparisons of the ligand binding properties of leghemoglobins with those from a wide variety of animal. myoglobins and hemoglobins have suggested that the small rates of $\mathrm{O}_{2}$ dissociation from soybean and lupin Lb are due to hydrogen bonding with His(E7) (Appleby et al. 1983; Mims et al. 1983; Stetzkowski et al. 1979; Rohlfs et al. 1988). Initial. electron paramagnetic resonance (EPR) experiments with cobalt-containing soybean $\mathrm{Lb}$ indicated weak hydrogen bonding at neutral. $\mathrm{pH}$ and a significant strengthening of this interaction at acid $\mathrm{pH}$ (Ikeda-Saito et al. 1981). More recent spin echo EPR studies confirmed this observation and further suggested that hydrogen bonding with the distal. histidine residue may occur only at low $\mathrm{pH}$ (Lee et al. 1993). Fuchsman and Appleby (1979) observed a single narrow IR band at $\mathrm{v}_{\mathrm{C}-\mathrm{O}}=1947 \mathrm{~cm}^{-1}$ for $\mathrm{Lb} a \mathrm{CO}$ at $\mathrm{pH}$ 7. This peak corresponds to the main band observed in sperm whale $\mathrm{MbCO}\left(\mathrm{v}_{\mathrm{C}-\mathrm{O}}=1945 \mathrm{~cm}^{-1}\right)$ and indicates a similar electrostatic environment around the bound ligand in both proteins. More recently, (Harutyunyan et al. 1995) reported a distance of $2.7 \AA$ between the second ligand atom and $\mathrm{N}^{\varepsilon}$ of His(E7) in lupin oxyleghemoglobin II, indicating a hydrogen bond between the imidazole group and bound $\mathrm{O}_{2}$. Thus, hydrogen bonding is thought to occur in leghemoglobins, especially at low $\mathrm{pH}$. However, the strength of this interaction and its exact role in governing the kinetics and equilibria of ligand binding to plant hemoglobins have not been established directly by site-directed mutagenesis.

Like all oxygen binding proteins, leghemoglobins must be in the $\mathrm{Fe}(\mathrm{II})$ oxidation state to bind oxygen. Within the root nodule, the protein is kept in the ferrous state by a reductase that catalyses the reduction of metleghemoglobin by NADH (Saari and Klucas 1984; Ji et al. 1994a; and Ji et al. 1994b). However, little is known about the molecular recognition and protein-protein interaction between the enzyme and its substrate. Soybean root nodules contain four leghemoglobin gene products, termed Lba, Lbc1, Lbc2 and Lbc3, and four variants of these four proteins in which the $\mathrm{N}$ termini are acetylated (Appleby 1984). The amino acid sequences and ligand binding properties of the four gene products are very similar (Martin et al. 1990). Several. studies have shown changes in the relative concentrations of the individual. leghemoglobins during plant growth, but the physiological. consequences of differential. expression and turnover are not well understood (Appleby 1984).

The expression of recombinant hemoglobins and myoglobins has allowed systematic studies of the structural. factors that regulate ligand binding to these proteins (Nagai et al. 1987; Mathews et al. 1991; Kloek et al. 1993; Springer et al. 1994). In order to carry out similar mechanistic studies, we have cloned Lba from a soy- bean cDNA library, inserted it into two expression vectors, and used both constitutive and inducible systems to express large quantities of protein. The crystal. structure of recombinant wild-type $\mathrm{Lb} a$ was determined to $2.2 \AA$ and compared with that of the native protein. The ligand binding, spectral, auto-oxidation and hemin dissociation properties of native and recombinant $\mathrm{Lb} a$ were also compared in detail. His61(E7) to Ala, Val, Leu and Phe mutations were constructed to examine the role of the distal. histidine residue in governing $\mathrm{O}_{2}$ binding. Finally, Tyr30(B10) to Phe and Leu65(E11) to Val. mutations were made to examine the structural. origin of differences between the rates of $\mathrm{O}_{2}$ binding to lupin LbII and soybean Lba.

\section{Results}

\section{Properties of wild-type Lba}

As described in Materials and Methods, the N-terminal. methionine residue of recombinant $\mathrm{Lb} a$ is removed post-translationally during constitutive expression in Escherichia coli TB1 cells, making the wild type recombinant $\mathrm{Lb} a$ chemically identical. with native $\mathrm{Lb} a$ (Figure $1)$. The absorbance spectra of wild-type metLb, deox$\mathrm{yLb}, \mathrm{LbO}_{2}$ and $\mathrm{LbCO}$ are identical. with those of the native protein (Table 1). The kinetic parameters for $\mathrm{O}_{2}, \mathrm{CO}$ and $\mathrm{NO}$ binding, hemin loss and auto-oxidation are also the same for the wild-type and native proteins (Table 2, Table 4, and Table 5). These data show that the protein obtained from E. coli TB1 cells is functionally and spectrally the same as native soybean leghemoglobin $a$. Lbs expressed in the inducible pET28a/BL21DE3 system are only partially processed, yielding a mixed sample of $\mathrm{N}$ met and "native-like" protein. However, the samples prepared from the pET28a/BL21DE3 system are kinetically and spectrally identical. with those prepared in TB1. Furthermore, it has been observed that addition of an entire N-terminal. S-tag (Novagen) domain has no effect on the kinetic or spectral. properties of the Lbs examined here (unpublished results).

\section{Crystal structure of wild type acetomet-Lba}

The crystallization system described by Vainshtein et al. (1975) was followed starting with aquomet wildtype $\mathrm{Lb} a$. Since $0.5 \mathrm{M}$ ammonium acetate is present in the solution, the acetomet form of the protein is produced in the crystals. The backbone and side-chain positions in the acetate complex of wild-type metLba are very similar to those of the nicotinate complex of native metLba (Ollis et al. 1983 and Ellis et al. 1997). An overlay of the backbone atoms plus the side-chains of the proximal. and distal. histidine residues of the two structures is shown in Figure 2. The native nicotinate structure is shown in yellow and molecule a of the two molecules in the asymmetric unit of the wild-type structure is shown in blue. The ligands have been removed for clarity. 


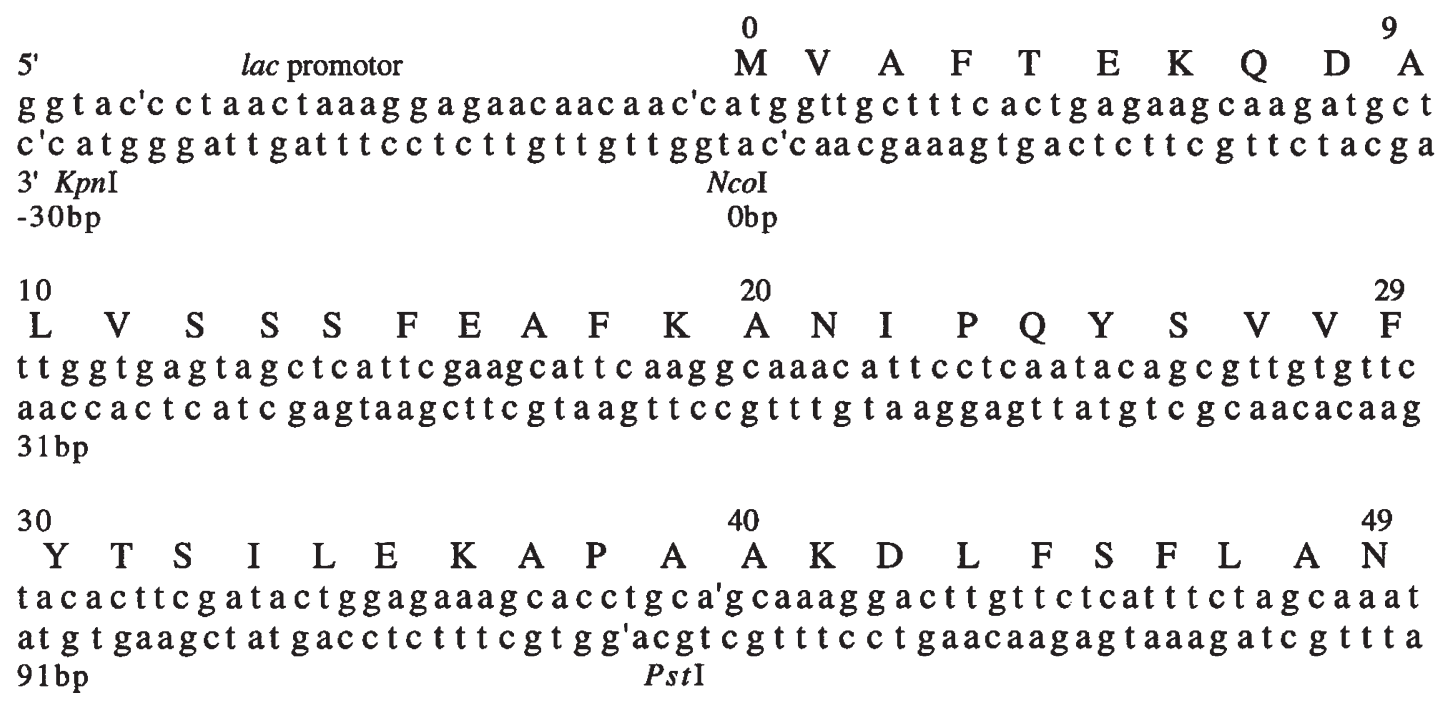

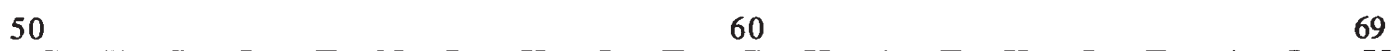

$\begin{array}{llllllllllllllllllll}G & V & D & P & T & N & P & K & \text { L } & T & G & H & A & E & K & L & F & A & L & V\end{array}$ ggagtagaccccact aat cct a g ctcacgggccatgctgaaagct t t tgcat tg tg c ctcatctggggtgat t aggat t c gagtg c c c g tacgact t t c gaaaacgta a c ac $150 \mathrm{bp}$

$\begin{array}{llllllllllllll}70 & & & 80 & & & & & & & & & & \end{array}$

$\begin{array}{llllllllllllllllllll}R & D & S & A & G & Q & \text { L } & K & A & S & G & T & V & \text { V } & \text { A } & \text { D } & \text { A } & \text { A } & \text { L } & G\end{array}$

c gtgactcagctggtcaact t aag caagtggaacagtggtggctgatgccgcact tggt

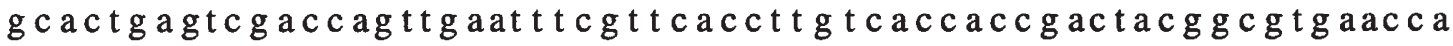
$209 \mathrm{bp}$

$90 \quad 100 \quad 109$ $\begin{array}{llllllllllllllllllll}S & V & H & A & Q & K & A & \text { V } & \text { T } & \text { D } & P & \text { Q } & \text { F } & \text { V } & \text { V } & \text { V } & \text { K } & \text { E } & \text { A } & \text { L }\end{array}$ tctgttcatgcccaaaagcagtcactgatcctcagt t c gtggtggt taagaagcact g a gac a a t a c g g t t t t c g t c agt gact aggagtca a c a c c a c caat t ct t c g t gac $268 \mathrm{bp}$

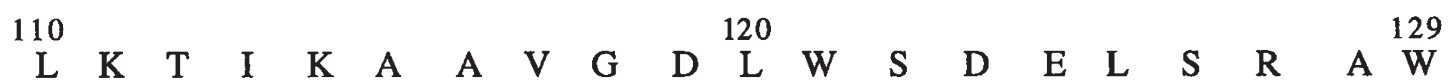

ct gaaaca a taagg cagcagt tggggacaatggagtgacgagt tgagccgtgcttgg gact t t g t t at t c c g t c g t caaccc tgt t acct cact gctcaactcggcacgaacc $327 \mathrm{bp}$

130
E

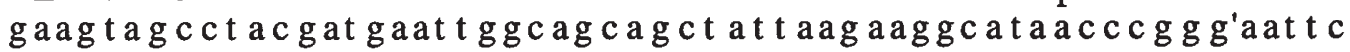
ct t catcggatgctact t a accgtcgt cgat a t t c t t c c g a t g g gcc t t a a'g $386 \mathrm{bp}$ EcoRI

Figure 1. The cDNA and amino acid sequence of recombinant soybean Lba in the pEMBL19+ plasmid pLba. The ribosome binding site lies between the 5' KpnI and NcoI restriction sites. The flanking 5' NcoI and 3' EcoRI restriction sites can be used to move the gene independently of the promoter region. The gene sequence corresponds with that observed for soybean Lba by HyldigNielsen et al. (1982).

These data show that the protein obtained from E. coli is structurally the same as native soybean Lba. The most significant differences between the two structures are in the positions of the heme group, distal. histidine residue, portions of the CD and FG corners, and part of the $F$ helix including His(F8). These differences appear to be due to the size of the coordinating ligand. In the native structure, the large nicotinate ring forces the distal. histidine residue out toward solvent and pushes the heme group downward. The proximal. histidine residue, $\mathrm{F}$ helix and FG corner rotate in order to compensate for this movement of the porphyrin ring. The $\mathrm{CD}$ corner also appears to move away from the bound ligand, but this region is either mobile or disordered in both structures. 
Table 1. Comparison of the wavelength maxima for the Soret absorbance bands of soybean $\mathrm{Lb}$ and sperm whale $\mathrm{Mb}$ at $\mathrm{pH} 7,25^{\circ} \mathrm{C}$.

\begin{tabular}{lccccc}
\hline & \multicolumn{5}{c}{ Wavelength peak (nm) } \\
\cline { 2 - 6 } Protein & $\mathrm{Fe}(\mathrm{II})$ & $\mathrm{Fe}(\mathrm{III})$ & $\mathrm{Fe}(\mathrm{II}) \mathrm{O}_{2}$ & $\mathrm{Fe}(\mathrm{II}) \mathrm{CO}$ & $\mathrm{Fe}(\mathrm{II}) \mathrm{NO}$ \\
\hline Native Lb & 428 & 403 & 409 & 416 & 418 \\
Wild-type Lb & 428 & 403 & 409 & 416 & 418 \\
H61L Lb & 425 & 395 & 414 & 419 & 418 \\
& & & & & \\
Wild-type Mb & 434 & 409 & 415 & 424 & 421 \\
H64L Mb & 434 & 393 & 415 & 425 & 421 \\
\hline
\end{tabular}

Figure 3 shows electron density around the heme binding site of wild-type Lba. The view is looking into the pocket from solvent with the distal. portion of the heme pocket located in the upper half of the drawing. The heme is shown in white, the acetate ligand in yellow and the protein chain in red. Well-resolved density for His61(E7) is seen next to the bound acetate group. Other prominent residues are (counter-clockwise): eu65(E11), located just behind His61(E7); and Phe44(CD1), located to the left of His61(E7), just above the heme plane.

The distal histidine residue in the structure of native soybean metLba appears to be hydrogen bonding with the carbonyl oxygen atom of the nicotinate ligand (Ollis et al. 1983). In the wild-type metLba structure, $\mathrm{N}^{\varepsilon}$ of His61(E7) is $2.64 \AA$ and $3.08 \AA$ away from the carbonyl oxygen atom of the acetate group in the two protein molecules found in the asymmetric unit. This proximity suggests that a hydrogen bond is also formed between bound acetate and the distal. histidine residue in the wild-type protein. Harutyunyan et al. (1995) have shown that a hydrogen bond occurs between the distal. histidine residue and the second coordinated ligand atom in the crystal. structure of lupin $\mathrm{LbO}_{2}$. Thus, in leghemo- globins, the distal. histidine residue appears to be quite flexible and is capable of interacting electrostatically with ligands of varying size.

\section{Role of His61(E7) in $\mathrm{O}_{2}$ binding}

Hydrogen bonding between bound oxygen and the distal. histidine residue in sperm whale myoglobin has been established by X-ray crystallography, and its effect on oxygen affinity has been determined in site-directed mutagenesis studies (Springer et al. 1994). Following the strategy of Springer et al. (1989), we replaced His61(E7) with Ala, Val, Leu and Phe to examine quantitatively how oxygen binding is affected by loss of hydrogen-bonding potential at this position in Lba. Table 2 presents a comparison of the effects of these E7 mutations on the rate and equilibrium constants for $\mathrm{O}_{2}$ binding to soybean $\mathrm{Lb} a$ with those observed previously for $\mathrm{O}_{2}$ binding to sperm whale myoglobin.

In general, the aliphatic replacements have a much smaller effect on $\mathrm{O}_{2}$ binding to leghemoglobin than to myoglobin. These differences are particularly striking when the oxygen dissociation rate constants are exam-

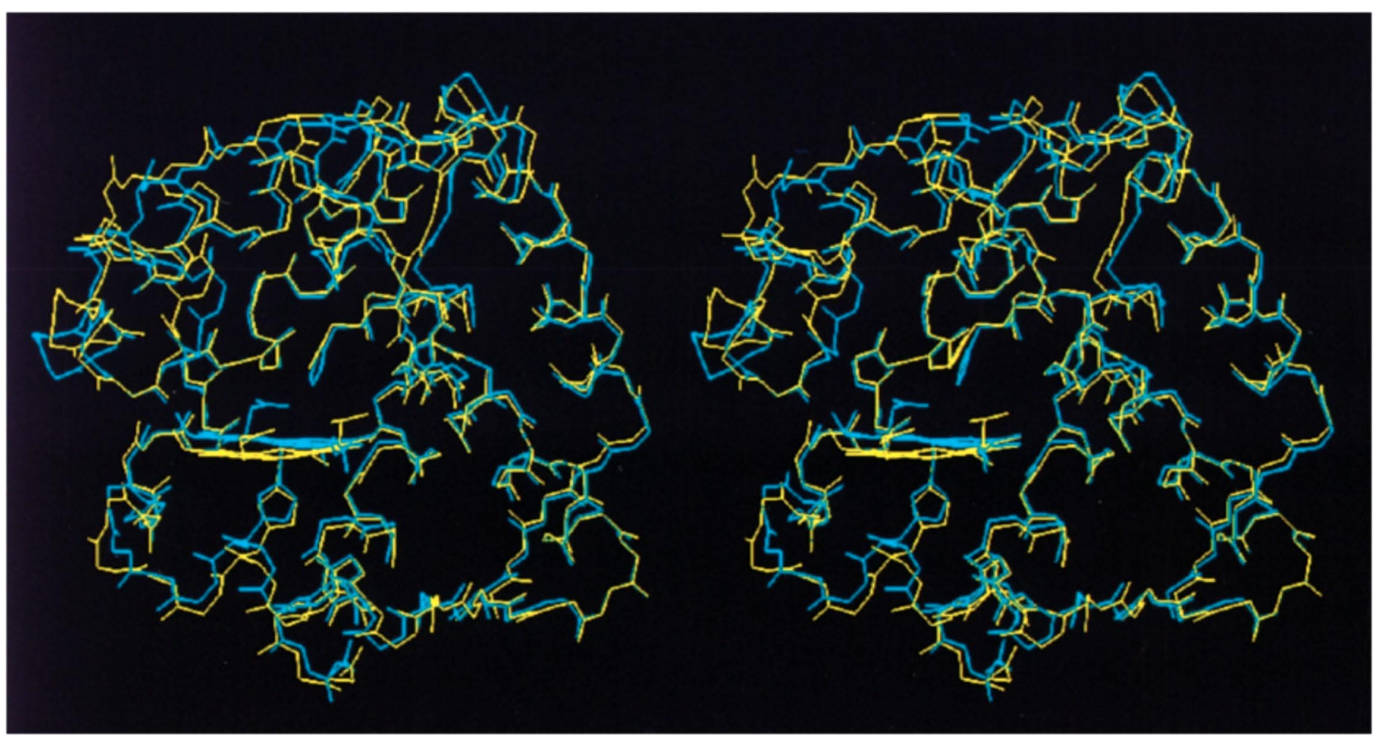

Figure 2. Crystal structure of the acetate complex of recombinant soybean metLba. A stereo overlay of the backbone atoms of the nicotinate complex of native metLba (yellow) and wild-type metLba (blue) including the proximal. and distal. histidine sidechains. The nicotinate and acetate ligands have been removed for clarity. 


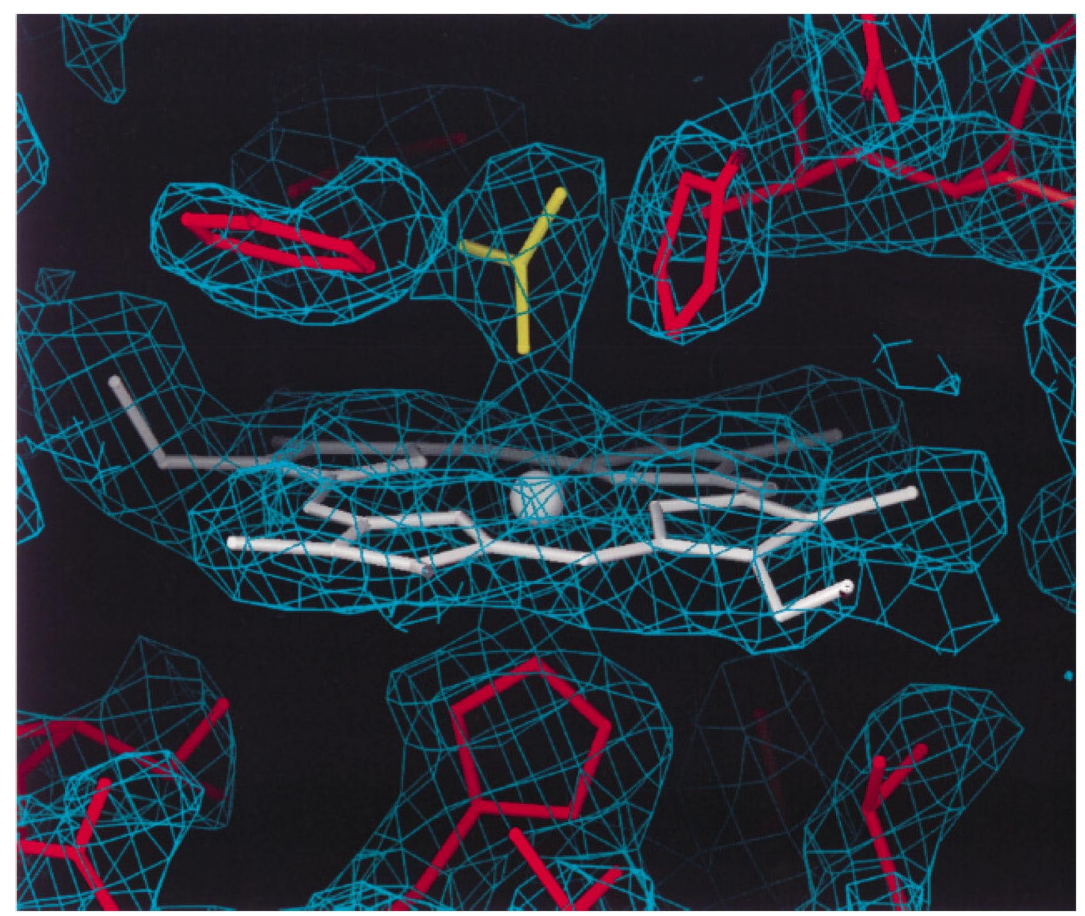

Figure 3. Electron density of the heme pocket in wild-type metLba-acetate. The heme prosthetic group is shown in white, the acetate ligand in yellow and the protein in red. The distal. histidine residue is within hydrogen-bonding distance of the carbonyl oxygen atom of the bound acetate group.

ined. Only the Phe-E7 mutation in Lba produces a large increase in $k_{\mathrm{O}_{2}}$, whereas in myoglobin all of the mutations cause at least 100 -fold increases in $k_{\mathrm{O}_{2}}$. These results clearly show that the hydrogen bond between oxygen and His-E7 in leghemoglobin is very weak at neutral. $\mathrm{pH}$ and not the main determinant of the high affinity of this protein for $\mathrm{O}_{2}$, in agreement with the EPR results of Ikeda-Saito et al. (1981) and Lee et al. (1993). The threeto fourfold increases in $k_{\mathrm{O}_{2}}$ observed for the $\mathrm{Val}(\mathrm{E} 7)$ and Leu(E7) Lba mutants are balanced by roughly equal. increases in $k_{\mathrm{O}_{2}}$ so there is little net change in overall oxygen affinity. The Ala(E7) and Phe(E7) mutations produce an increase and decrease, respectively, in $\mathrm{K}_{\mathrm{O}_{2}}$ with respect to the wild-type protein. These latter changes seem to imply that the E7 residue may sterically hinder the bound ligand. However, an exact interpretation of these results will require high-resolution crystal. structures of the proteins. Regardless, it is clear that the polarity of His(E7) plays a much smaller role in regulating ligand binding to leghemoglobin than to myoglobin.
The effects of $\mathrm{pH}$ on oxygen binding to native, wildtype and E7 mutants of soybean leghemoglobin are presented in Table 3. As shown by Appleby et al. (1983), when the $\mathrm{pH}$ is decreased from 7 to 5 , the rate constant for oxygen dissociation from $\mathrm{Lb} a$ decreases twofold with no change in the association rate constant. The resultant increase in affinity at low $\mathrm{pH}$ has been attributed to a strengthening of the hydrogen bond between His61 and bound ligand. The apolar mutants of $\mathrm{Lb} a$ show no $\mathrm{pH}$ dependence (Table 3). These mutagenesis results support the view that His61 plays a role in the $\mathrm{pH}$ dependence of $\mathrm{O}_{2}$ binding to native leghemoglobin and that hydrogen bonding to the bound ligand is enhanced under acidic conditions.

\section{$\mathrm{CO}$ and NO binding}

The rate and equilibrium constants for carbon monoxide (CO) and nitric oxide (NO) binding to Lba, sperm whale myoglobin and the corresponding Leu(E7) mutants are

Table 2. The effects of apolar substitutions at position E7 on the rate and equilibrium constants of $\mathrm{O}_{2}$ binding to soybean $\mathrm{Lb} a$ and sperm whale $\mathrm{Mb}$ at $\mathrm{pH} 7,20^{\circ} \mathrm{C}$.

\begin{tabular}{|c|c|c|c|c|c|c|}
\hline \multirow{2}{*}{$\begin{array}{l}\text { Residue at } \\
61(E 7)\end{array}$} & \multicolumn{2}{|c|}{$\begin{array}{c}k_{\mathrm{O}_{2}}^{\prime} \\
\mu \mathrm{M}^{-1} \mathrm{~s}^{-1}\end{array}$} & \multicolumn{2}{|c|}{$\begin{array}{l}k_{\mathrm{O}_{2}} \\
\mathrm{~s}^{-1}\end{array}$} & \multicolumn{2}{|c|}{$\begin{array}{c}K_{\mathrm{O}_{2}} \\
\mu \mathrm{M}^{-1}\end{array}$} \\
\hline & $\mathrm{Lb}$ & $\mathrm{Mb}$ & $\mathrm{Lb}$ & $\mathrm{Mb}$ & $\mathrm{Lb}$ & $\mathrm{Mb}$ \\
\hline His(wild-type) & 130 & 17 & 5.6 & 15 & 23 & 1.1 \\
\hline Ala & 290 & 53 & 3.1 & 2300 & 94 & 0.023 \\
\hline Val & 280 & 110 & 27 & 10000 & 10 & 0.011 \\
\hline Leu & 400 & 98 & 24 & 4100 & 17 & 0.023 \\
\hline Phe & 130 & 75 & 280 & 10000 & 0.45 & 0.0075 \\
\hline
\end{tabular}

Data for sperm whale myoglobin were taken from Springer et al. (1994). 
Table 3. Dependence of $\mathrm{O}_{2}$ binding parameters on $\mathrm{pH}$ for native, wild-type, and Leu-E7 soybean $\mathrm{Lb} a$ at $20^{\circ} \mathrm{C}$.

\begin{tabular}{|c|c|c|c|c|c|c|}
\hline \multirow[b]{2}{*}{$\begin{array}{l}\text { Soybean } \\
\text { Lb }\end{array}$} & \multicolumn{3}{|c|}{$\mathrm{pH} 7$} & \multicolumn{3}{|c|}{ pH 5} \\
\hline & $\begin{array}{c}k_{\mathrm{O}_{2}}^{\prime} \\
\left(\mu \mathrm{M}^{-1} \mathrm{~s}^{-1}\right)\end{array}$ & $\begin{array}{c}k_{\mathrm{O}_{2}} \\
\left(\mathrm{~s}^{-1}\right)\end{array}$ & $\begin{array}{c}K_{\mathrm{O}_{2}} \\
\left(\mu \mathrm{M}^{-1}\right)\end{array}$ & $\begin{array}{c}k_{\mathrm{O}_{2}}^{\prime} \\
\left(\mu \mathrm{M}^{-1} \mathrm{~s}^{-1}\right)\end{array}$ & $\begin{array}{r}k_{\mathrm{O}_{2}} \\
\left(\mathrm{~s}^{-1}\right)\end{array}$ & $\begin{array}{c}K_{\mathrm{O}_{2}} \\
\left(\mu \mathrm{M}^{-1}\right)\end{array}$ \\
\hline Native & 130 & 5.6 & 23 & 140 & 2.7 & 51 \\
\hline Wild-type & 130 & 5.6 & 23 & 130 & 2.2 & 60 \\
\hline H61A & 290 & 3.1 & 94 & 250 & 2.7 & 92 \\
\hline $\mathrm{H} 61 \mathrm{~V}$ & 280 & 27 & 10 & 280 & 28 & 10 \\
\hline H61L & 400 & 24 & 17 & 470 & 25 & 19 \\
\hline $\mathrm{H} 61 \mathrm{~F}$ & 130 & 280 & 0.45 & 120 & 230 & 0.54 \\
\hline
\end{tabular}

presented in Table 4. Replacement of the distal. histidine residue with Leu increases the association rate constants for $\mathrm{CO}$ and $\mathrm{NO}$ binding to both proteins, but again the effects are much greater in myoglobin. The rate constants for $\mathrm{CO}$ and $\mathrm{NO}$ dissociation are largely unaffected by the Leu(E7) replacement. For both ligands, wild-type $\mathrm{Lb} a$ has larger association rate constants and smaller dissociation rate constants than wild-type myoglobin. These results point out that with or without a distal. histidine residue, leghemoglobin is inherently much more reactive than myoglobin.

\section{Autooxidation and hemin loss}

A comparison of resistances to auto-oxidation and hemin dissociation is given in Table 5. Brantley et al. (1993) have shown that the rate constants for auto-oxidation of myoglobin mutants correlate inversely with $\mathrm{O}_{2}$ affinity. Thus, we expected Lba to auto-oxidize slowly due to its high $\mathrm{O}_{2}$ affinity. However, the opposite effect was observed; $k_{\text {autoox }}$ for $\mathrm{Lb} a$ is about fourfold greater than that of wild-type sperm whale $\mathrm{Mb}$. This result does correlate with a much weaker hydrogen bond between bound $\mathrm{O}_{2}$ and His(E7) in leghemoglobin. Brantley et al. (1993) showed that this polar interaction inhibits protonation of the $\mathrm{Fe}-\mathrm{O}_{2}$ complex and its subsequent dismutation into ferric iron and the neutral. superoxide radical. Both myoglobin and leghemoglobin show a marked increase in $k_{\text {autoox }}$ with decreasing $\mathrm{pH}$, presumably due to protonation of bound $\mathrm{O}_{2}$.
The rate constant for hemin dissociation from native and wild-type $\mathrm{Lb} a$ is $\sim 6 \mathrm{~h}^{-1}$ at $\mathrm{pH} 7.0,37^{\circ} \mathrm{C}$. This rate is 600 times faster than that for myoglobin under the same conditions and, in combination with the increased autooxidation rate, results in a much less stable holoprotein (Hargrove and Olson 1996). Lba also has a much larger temperature dependence for hemin dissociation than myoglobin $\left(E_{\mathrm{a}} \approx 33 \mathrm{kcal} / \mathrm{mol}\right.$ for aquometLba versus $E_{\mathrm{a}} \approx$ $8 \mathrm{kcal} / \mathrm{mol}$ for sperm whale aquometMb at pH 7; (Hargrove et al. 1994); and unpublished results). As shown in Table $5, k_{-\mathrm{H}}$ for met $\mathrm{Lb} a$ is $\sim 0.8 \mathrm{~h}^{-1}$ at $20^{\circ} \mathrm{C}$, which is roughly tenfold less than the rate observed at $37^{\circ} \mathrm{C}$. The rate constant for hemin loss from myoglobin decreases by only a factor of $\sim 2$ when the temperature is decreased from 37 to $20^{\circ} \mathrm{C}$ at both $\mathrm{pH} 5.0$ and $\mathrm{pH} 7.0$ ((Hargrove et al. 1994); and unpublished results).

The rates of hemin loss from the distal. histidine mutants of $\mathrm{Lb} a$ are too fast to be measured conveniently at $37^{\circ} \mathrm{C}$. As a result, comparisons between mutant and wild-type leghemoglobins were measured at $20^{\circ} \mathrm{C}$. The distal. histidine residue of Lba clearly stabilizes bound hemin, as shown by the H61L substitution, which increases the rate constant for hemin dissociation $\sim 50$-fold. A similar effect occurs when His(E7) is replaced by Leu in myoglobin. A large part of this effect is probably due to loss of the coordinated water molecule from the ferric H61L protein. Both Leu-E7 metMb and metLba show a broad absorbance band centered at $395 \mathrm{~nm}$, which is characteristic of 5-coordinated ferric proteins (Table 1; Quillin et al. 1993). The $\mathrm{pH}$ dependence of hemin dis-

Table 4. Comparison of the $\mathrm{CO}$ and NO binding parameters of soybean $\mathrm{Lb} a$ and sperm whale $\mathrm{Mb}$ at $\mathrm{pH} 7,20^{\circ} \mathrm{C}$

\begin{tabular}{lcccccr}
\hline Protein & $\begin{array}{c}k_{\mathrm{CO}}^{\prime} \\
\left(\mu \mathrm{M}^{-1} \mathrm{~s}^{-1}\right)\end{array}$ & $\begin{array}{c}k_{\mathrm{CO}} \\
\left(\mathrm{s}^{-1}\right)\end{array}$ & $\begin{array}{c}K_{\mathrm{CO}} \\
\left(\mu \mathrm{M}^{-1}\right)\end{array}$ & $\begin{array}{c}k_{\mathrm{NO}}^{\prime} \\
\left(\mu \mathrm{M}^{-1} \mathrm{~s}^{-1}\right)\end{array}$ & $\begin{array}{c}k_{\mathrm{NO}} \\
\left(\mathrm{s}^{-1}\right)\end{array}$ & \multicolumn{1}{c}{$\begin{array}{c}K_{\mathrm{NO}} \\
\left(\mu \mathrm{M}^{-1}\right)\end{array}$} \\
\hline Native Lb & 17 & 0.0078 & 2200 & 170 & 0.00002 & $9,000,000$ \\
Wild-type Lb & 15 & 0.0084 & 1800 & 190 & 0.00002 & $9,000,000$ \\
H61L Lb & 170 & 0.0024 & 72,000 & 320 & 0.00002 & $16,000,000$ \\
Wild-type Mb & 0.51 & 0.019 & 27 & 22 & 0.00010 & 220,000 \\
H64L Mb & 26 & 0.024 & 1100 & 190 & 0.00013 & $1,500,000$ \\
\hline
\end{tabular}

Data for sperm whale myoglobin were taken from Springer et al. (1994). 
Table 5. Comparison of the rate constants for hemin dissociation $\left(k_{-\mathrm{H}}\right)$ from and autooxidation $\left(k_{\text {autoox }}\right)$ of soybean $\mathrm{Lb} a$ and sperm whale $\mathrm{Mb}$

\begin{tabular}{lccccc}
\hline & \multicolumn{2}{c}{$k_{\text {autoox }}\left(\mathrm{h}^{-1}\right)$ at $37^{\circ} \mathrm{C}$} & & \multicolumn{2}{c}{$k_{-\mathrm{H}}\left(\mathrm{h}^{-1}\right)^{\mathbf{b}}$ at $20^{\circ} \mathrm{C}$} \\
\cline { 2 - 3 } \cline { 5 - 6 } Protein & $\mathrm{pH} 7$ & $\mathrm{pH} 5$ & & $\mathrm{pH} 7$ & $\mathrm{pH} \mathrm{5}$ \\
\hline Native Lb & 0.2 & 1.6 & 0.7 & 1.3 \\
Wild-type Lb & 0.2 & 3.0 & & 0.9 & 3.0 \\
H61L Lb & 0.3 & 6.6 & & 47 & 45 \\
Wild-type Mb & 0.055 & 2.4 & & $0.005^{\mathrm{c}}(0.01)$ & $0.4(1.0)$ \\
H64L Mb & 10 & $200^{\mathrm{a}}$ & & $0.094^{\mathrm{c}}(0.20)$ & $5.2^{\mathrm{c}}(11)$ \\
\hline
\end{tabular}

The $k_{\text {autoox }}$ values for $\mathrm{MbO}_{2}$ were taken from Brantley et al. (1993) and the values of $k_{-\mathrm{H}}$ for metMb from Hargrove et al. (1996b). Rates of auto-oxidation were measured in the presence of $1 \mathrm{mM}$ EDTA, catalase, and superoxide dismutase as described by Brantley et al. (1993). The $k_{-\mathrm{H}}$ values in parentheses for metMb were measured at $37^{\circ} \mathrm{C}$ by Hargrove et al. (1996b) and Hargrove et al. (1994).

a The value of $k_{\text {autoox }}$ for Leu(E7) $\mathrm{Mb}$ at $\mathrm{pH} 5$ was estimated assuming the same $\mathrm{pH}$ dependence as is observed for the $\mathrm{Val}(\mathrm{E} 7) \mathrm{Mb}$ mutant by Brantley et al. (1993).

b The rates of hemin loss from leghemoglobin were measured at $20^{\circ} \mathrm{C}$ to allow comparison with mutant Lbs, which lose heme too rapidly at $37^{\circ} \mathrm{C}$.

${ }^{c}$ The rates of hemin loss at $20^{\circ} \mathrm{C}$ were computed using the $k_{-\mathrm{H}}$ value at $37^{\circ} \mathrm{C}$ and an activation energy of $8.0 \mathrm{kcal} / \mathrm{mol}$. The values in parentheses were measured at $37^{\circ} \mathrm{C}$ (Hargrove et al., 1996b).

sociation from Lba is much smaller than that of myoglobin. The resistances of both proteins to auto-oxidation and hemin loss are similar at $\mathrm{pH} 5$, whereas at $\mathrm{pH} 7$ sperm whale myoglobin is much more stable.

\section{Comparison with lupin Lbll}

As shown in Table 6, the association and dissociation rate constants for $\mathrm{O}_{2}$ binding to lupin LbII are three- to fivefold greater than the corresponding parameters for soybean Lba. This implies more rapid rates of ligand entry into and exit from the distal. pocket of the lupin protein. Both proteins contain His(E7) and Phe(CD1). In lupin LbII the B10 and E11 residues are smaller, Phe and Val, respectively, versus Tyr and Leu in soybean leghemoglobin. However, this decrease in size does not appear to account for the ligand binding differences. Mutation of Leu65(E11) to Val. has little effect on $\mathrm{O}_{2}$ binding to soybean $\mathrm{Lb} a$, and the Tyr30(B10) to Phe substitution causes decreases, not increases, in $k_{\mathrm{O}_{2}}^{\prime}$ and $k_{\mathrm{O}_{2}}$ (Table 6). As suggested by Gibson et al. (1989), the differences in kinetic behavior among leghemoglobins appear to be due to amino acid changes remote from the ligand binding site. The increase in affinity due to the $\mathrm{Y} 30 \mathrm{~F}$ substitution is striking and suggests that an in-depth study of the role of this residue in ligand binding will be rewarding.

Table 6. Comparison of the rate constants for $\mathrm{O}_{2}$ binding to soybean $\mathrm{Lb} a$ and Lupin LbII at $\mathrm{pH} 7,20^{\circ} \mathrm{C}$.

\begin{tabular}{lccc}
\hline Protein & $\begin{array}{c}k_{\mathrm{O}_{2}}^{\prime} \\
\left(\mu \mathrm{M}^{-1} \mathrm{~s}^{-1}\right)\end{array}$ & $\begin{array}{c}k_{\mathrm{O}_{2}} \\
\left(\mathrm{~s}^{-1}\right)\end{array}$ & $\begin{array}{c}K_{\mathrm{O}_{2}} \\
\left(\mu \mathrm{M}^{-1}\right)\end{array}$ \\
\hline Lupin LbII & 320 & 25 & 13 \\
Soybean Lba & 130 & 5.6 & 23 \\
Soybean Lba (L65V) & 180 & 5.8 & 30 \\
Soybean Lba (Y30F) & 79 & 0.75 & 100 \\
\hline
\end{tabular}

The rate constants for lupin LbII were taken from Gibson et al. (1989).

\section{Discussion}

The crystal. structure of recombinant $\mathrm{Lb} a$ and the data reported in Table 1 and Table 4 show that the protein expressed in E. coli TB1 cells is functionally and structurally identical. with that of native Lba. It is unclear why the $\mathrm{N}$-terminal. methionine residue is removed from this protein when wild-type myoglobin grown under the same conditions is expressed with the N-Met still attached (Springer and Sligar 1987; Phillips et al. 1990). The N-terminal. amino acid sequences of the two proteins are similar (Lba, VAFTE-; Mb, VLSEG-). There is no clear explanation for the difference in post-translational. processing during constitutive expression.

Leghemoglobin is much less stable than myoglobin due to a fourfold higher rate of auto-oxidation and a $\sim 600$-fold higher rate of hemin loss at $\mathrm{pH} 7,37^{\circ} \mathrm{C}$. The rate constant for hemin loss of the H61L Lba mutant, $\sim 50 \mathrm{~h}^{-1}$, is in the range of that for H93G sperm whale myoglobin, which lacks a covalent bond between the heme and globin (Hargrove et al. 1996a). The increase in $k_{-\mathrm{H}}$ caused by the H61L mutation suggests that the distal. histidine residue of $\mathrm{Lb}$ stabilizes bound heme by hydrogen bonding to a coordinated water molecule as is observed in myoglobin. The decreased stability of $\mathrm{Lb} a$ probably accounts for the lower yields in the constitutive expression (TB1) system relative to that of myoglobin. Purification of leghemoglobin in the presence of $\mathrm{CO}$ or other distal. ligands prevents heme loss and greatly increases protein yields in both the constitutive and inducible expression systems.

The oxygen association rate constants for leghemoglobins are very fast, of the order of $10^{8} \mathrm{M}^{-1} \mathrm{~s}^{-1}$, and are close to the rate expected for a diffusion-limited association reaction with an unhindered model heme $\left(k_{\text {diffusion }}^{\prime} \approx 5 \times 10^{8} \mathrm{M}^{-1} \mathrm{~s}^{-1}\right.$, (Reisberg and Olson 1980)). 
Gibson et al. (1989) also suggested that the Lb rates may be the fastest possible for ligand association to a myoglobin-like protein. The high rates of ligand binding to $\mathrm{Lb}$ result in part from a very reactive heme iron atom as has been demonstrated with laser photolysis experiments (Stetzkowski et al. 1985; Gibson et al. 1989). Harutyunyan et al. (1995) have shown that the proximal. histidine residue in lupin $\mathrm{Lb}$ is much more free to rotate and move toward the heme plane than in myoglobin. These results provide a structural. explanation for the high reactivity of leghemoglobins. The heme pocket of $\mathrm{Lb} a$ is also more flexible and kinetically accessible than those of myoglobin and other heme proteins (Rohlfs et al. 1988). This has been demonstrated by many techniques and is exemplified by the ability of $\mathrm{Lb} a$ to bind large ligands such as imidazole, nicotinate, and long-chain alkyl isocyanides, which do not bind tightly to myoglobin or hemoglobin (Stetzkowski et al. 1979; Kong et al. 1983; Mims et al. 1983).

Even though the bimolecular rate constants are large, His(E7) still appears to offer some resistance to ligand association. The distal. heme pocket of the deoxy forms of myoglobin and lupin leghemoglobin both contain a non-coordinated water molecule that hydrogen bonds to His(E7) (Quillin et al. 1993; Harutyunyan et al. 1995). This water molecule must be displaced before other ligands can bind. The increased association rate constants for oxygen binding to the H61A, H61V, and H61L mutants of $\mathrm{Lb} a$ are probably due to the loss of water in the deoxy forms of these proteins. The same mutations produce even larger increases in $k_{\mathrm{O}_{2}}^{\prime}$ when constructed in sperm whale myoglobin (Quillin et al. 1993; Table 2).

The functional. evidence for a hydrogen bond between bound $\mathrm{O}_{2}$ and His(E7) in leghemoglobin is equivocal. at $\mathrm{pH}$ 7.0. The Ala, Val. and Leu(E7) substitutions do not produce large decreases in $\mathrm{K}_{\mathrm{O}_{2}}$ as is observed in myoglobin. However, the $\mathrm{pH}$ dependence of $\mathrm{O}_{2}$ dissociation from leghemoglobin does appear to involve the distal. histidine residue. Decreasing the $\mathrm{pH}$ from 7 to 5 causes a twofold increase in $\mathrm{O}_{2}$ affinity when the E7 residue is histidine but has no effect when the E7 residue is apolar. This result suggests that hydrogen bonding occurs under acid conditions, but even at low $\mathrm{pH}$, the strength of this interaction is still much less than that observed in myoglobin.

The $\beta$ subunit of R-state human hemoglobin shows high rates of ligand association, and replacement of the distal. histidine residue with either Gly or Phe has little effect on $\mathrm{O}_{2}$ binding (Mathews et al. 1989). Thus both soybean $\mathrm{Lb} a$ and R-state human $\beta$ subunits have evolved mechanisms for stabilizing bound $\mathrm{O}_{2}$ and inhibiting auto-oxidation that do not involve a strong hydrogen bond with His(E7). In contrast, strong favorable polar interactions occur in the distal. pockets of all mammalian myoglobins and the a subunit of human hemo- globin. However, the distal. histidine residue is very important for retaining heme in leghemoglobin and human $\beta$ subunits. Replacing the distal. histidine residue with smaller apolar residues causes $\geq 50$-fold increases in the rate of hemin loss from metLba and ferric $\beta$ subunits, explaining the high degree of conservation of His(E7) in these proteins (Table 5; Hargrove et al. 1994).

\section{Materials and methods}

A full-length cDNA for Lba was isolated from a soybean nodule cDNA library using anti-Lba antibodies as a probe (Ji et al. 1994a; Sambrook et al. 1989). Phage ( $\lambda$-GT11) containing the soybean Lba insert were placed in $E$. coli, harvested, and the DNA isolated. Lba cDNA was excised and ligated into pBluescript $\mathrm{K}+$ (Invitrogen). To obtain the coding region, polymerase chain reaction (PCR) primers containing a NcoI site at the starting ATG codon and an EcoRI restriction site downstream of the TAA stop codon were used to amplify the Lba gene from the pBluescript-Lba vector. PCR-amplified products were purified by agarose gel electrophoresis and ligated into a pCRII vector (Invitrogen). After transformation, an E. coli colony containing the pCRII-Lba construct was used to obtain purified plasmid with the NcoI-Lba-EcoRI sequence. This gene fragment was removed from pCRII, purified from an agarose gel, and ligated into pACYC184. A duplex oligonucleotide of the constitutive lac promoter used by Springer and Sligar (1987) was constructed with the following sequence of restriction sites: 5' Bsu36I-KpnI-lac promoterNcoI 3'. The pACYC184-Lba plasmid was cut with NcoI and Bsu36I, and the oligonucleotide containing the lac promoter was ligated to the $\mathrm{Lb} a \mathrm{cDNA}$. This lac promoter-Lba construct was removed from pACYC184 and ligated into pEMBL19+ using the flanking $\mathrm{KpnI} / \mathrm{EcoRI}$ sites.

The initial cDNA product cloned in this manner contained two base-pair differences compared to the Lba sequence reported by Hyldig-Nielsen et al. (1982). These changes were probably introduced during the PCR reaction used to amplify the cDNA. The gene was corrected to the native sequence by two rounds of site-directed mutagenesis using the Kunkel (1985) method. The resulting plasmid, pLba, contains the native Lba cDNA sequence in pEMBL19+ under control of the lac promoter (Figure 1). The Kunkel method of mutagenesis was also used to generate the B10, E7 and E11 mutants starting from the "corrected" wild-type Lba gene.

\section{Expression of wild-type and mutant Lbas}

E. coli TB-1 cells were transformed with $\mathrm{pLb} a$ and grown in LB medium (with ampicillin) at $37^{\circ} \mathrm{C}$. The final. yield of purified leghemoglobin $(\sim 0.6 \mathrm{mg} / \mathrm{l})$ was roughly one-seventh of that for sperm whale myoglobin expressed under the same conditions $(\sim 4 \mathrm{mg} / \mathrm{l})$. H61F, H61V and H61A proteins showed no appreciable expression in the lac promoter-TB1 system. Consequently, the NcoI-Lba-EcoRI fragment was cloned into pET28a (Novagen) for high-level, inducible expression in $E$. coli BL21DE3 cells. Shake flasks of BL21DE3 cells transformed with the pET28a-Lba vector were grown to an absorbance of $\sim 0.6$ in $2 \times \mathrm{YT}_{\text {medium }}$ at $33^{\circ} \mathrm{C}$, induced with $1 \mathrm{mM}$ isopropyl$\beta$, D-thiogalactopyramoside and incubated for an additional. four hours. Apo-Lba was found in the supernatant and pellet of the cell lysis mixture. Protein was recovered from the lysis 
pellet by dissolution in $6 \mathrm{M}$ guanidinium chloride followed by dialysis into $20 \mathrm{mM}$ Tris ( $\mathrm{pH} 8.0$ ). Holoprotein was reconstituted by the addition of CO-heme or imidazole-hemin to the soluble and pellet fractions of the lysis mixture. The final. yield of wild-type or mutant Lba was $\sim 10 \mathrm{mg} / \mathrm{l}$ of medium. Reconstituted holo-Lba was precipitated with $90 \%$ saturated ammonium sulfate for further purification.

Regardless of the method of expression, recombinant Lba was purified as described by Jun et al. (1994) with the following modifications. The $90 \%$ saturated ammonium sulfate Lba pellet was resuspended in $1.8 \mathrm{M}$ ammonium sulfate and loaded directly onto a phenyl Sepharose column, and the protein was not oxidized prior to G-75 chromatography. Purified $\mathrm{Lb} a$ was in the $\mathrm{CO}$ or met-imidazole form (depending on the method of reconstitution) and had a Soret to $280 \mathrm{~nm}$ absorbance ratio greater than 4 . Native Lba was purified from soybean root nodules using the method of Jun et al. (1994). N-terminal. sequencing of the purified Lbs was performed at the UNL-Protein Core Facility on an ABI-494 Procise sequencer using a manufacturer-supplied protocol.

\section{Crystallography of wild-type Lba}

Crystals of the acetate complex of wild-type metLba were grown at room temperature to $0.5 \mathrm{~mm} \times 0.05 \mathrm{~mm} \times 0.05 \mathrm{~mm}$ in three to five days using the hanging drop method. The starting concentration of metLba was $1 \mathrm{mM}$ in $0.1 \mathrm{M}$ sodium phosphate ( $\mathrm{pH}$ 6.0). The precipitant was $2.4 \mathrm{M}$ ammonium sulfate, $0.5 \mathrm{M}$ ammonium acetate at pH 6.8 (Vainshtein et al. 1975). Xray diffraction data were collected at room temperature on an $\mathrm{R}$-axis IIc imaging plate system using copper Ka radiation from a Siemens rotating anode operating at $50 \mathrm{mV}$ and $90 \mathrm{~mA}$. Crystals were in the $P 22_{1} 2_{1} 2_{1}$ space group. The data were $90 \%$ complete at the limiting resolution of $2.2 \AA$, with an $R_{\text {merge }}$ of $10.3 \%$. Phases were determined by molecular replacement using XPLOR (Brunger 1987) starting with the coordinates for the structure of Lba -nicotinate provided by Dr Paul Ellis (PDB file 1fsl; Ollis et al. 1983; Ellis et al. 1997). Two molecules related by a 2-fold non-crystallographic symmetry axis were present in the asymmetric unit. After several. cycles of refinement, manual. fitting and solvent addition, the crystallographic $R$-factor converged to $19.8 \%\left(R_{\text {free }}=29.7 \%\right)$ with root-mean-square deviations of $0.018 \AA$ in bond lengths, $1.93^{\circ}$ in bond angles, $21.36^{\circ}$ in dihedral. angles and $2.29^{\circ}$ in improper angles. Molecule a of the two molecules in the asymmetric unit was used to produce Figure 2 and Figure 3. The coordinates of the structure of wildtype metLba-acetate have been assigned number 1bin in the Protein Data Bank at the Brookhaven National. Laboratory.

\section{Spectroscopic and kinetic characterization of wild-type and mutant Lba}

Absorbance spectra were measured using a SLM 3000 diode array spectrophotometer. $\mathrm{LbCO}$ was prepared by diluting metLb into a cuvette containing $20 \mathrm{mM}$ Tris ( $\mathrm{pH}$ 8.0) buffer equilibrated with $1 \mathrm{~atm} \mathrm{CO}$ and an excess of sodium dithionite. MetLb was formed by the reaction of ferrous $\mathrm{Lb}$ with potassium ferricyanide followed by chromatography on a Sephadex G-25 column equilibrated in $20 \mathrm{mM}$ Tris ( $\mathrm{pH} 8.0$ ). $\mathrm{LbO}_{2}$ was produced by the reduction of metLb with sodium dithionite followed by G-25 chromatography in the presence of oxygen. DeoxyLba was produced by the addition of several. granules of sodium dithionite to a cuvette containing metLb in anaerobic buffer.
The rate constants for $\mathrm{O}_{2}, \mathrm{CO}$ and $\mathrm{NO}$ binding were measured using established rapid mixing and laser photolysis methods (Olson 1981; Quillin et al. 1995; Moore and Gibson 1976). $\mathrm{O}_{2}$ and $\mathrm{CO}$ association rate constants at $\mathrm{pH} 5.0$ were measured in $100 \mathrm{mM}$ sodium acetate $\left(\mathrm{pH}\right.$ 5.0). $\mathrm{O}_{2}$ dissociation at $\mathrm{pH} 5$ was measured by mixing a $\mathrm{LbO}_{2}$ sample in $10 \mathrm{mM}$ potassium phosphate $(\mathrm{pH} 7.0)$ with $100 \mathrm{mM}$ sodium acetate $(\mathrm{pH}$ 5.0), equilibrated with 1 atm CO (Appleby et al. 1983).

Rate constants for hemin dissociation and auto-oxidation were measured as described by Hargrove et al. (1994) and Brantley et al. (1993), respectively. Hemin dissociation from H61L Lba was measured in a Gibson-Dionex stopped-flow apparatus as described by Hargrove et al. (1996a). Mes (2-(N-mo rpholino)ethanesulfonic acid) was used as the buffer at $\mathrm{pH} 5$ for measurement of hemin dissociation because acetate coordination to metLb markedly inhibits this reaction.

\section{Acknowledgements}

This work was supported by United States Public Health Service grants GM35649 and HL-47020, grant C-612 from the Robert A. Welch Foundation, and the W. M. Keck Foundation (J.S.O.), grant 003604-025 from the State of Texas Advanced Technology Program (G.N.P./J.S.O.), a National. Institutes of Health Postdoctoral. Fellowship ARO8355 (E.A.B.), NSF grant OSR-92552255 (R.V.K.), USDA-CREES 95-37305-2441 (R.V.K./ G.S.), and the Nebraska Research Initiative (G.S.). R.A.P. was partially supported by DGAPA (Direccion General. de Asuntos del Personal. Academico)-UNAM and CoNaCyT (Consejo Nacional de Cieneia y Tecnologia), Mexico. We also thank M. Ikeda-Saito, C. Appleby and A. Wilkinson for reading the original. manuscript and making helpful suggestions.

\section{References}

Appleby (1984) - C. A. Appleby, Leghemoglobins and Rhizobium respiration. Annu. Rev. Plant Physiol 35 (1984), pp. 443-478.

Appleby (1992) - C. A. Appleby, The origin and functions of haemoglobin in plants. Sci. Prog 76 (1992), pp. 365-398.

Appleby et al.(1983) - C.A., Appleby, J.H. Bradbury, R.J. Morris, B.A. Wittenberg, J.B. Wittenberg and P.E. Wright, Leghemoglobin. J. Biol. Chem 258 (1983), pp. 2254-2259.

Brantley et al.(1993) - R.E. Brantley, S.J. Smerdon, A.J. Wilkinson, E.W. Singleton and J.S. Olson, The mechanism of autooxidation of myoglobin. J. Biol. Chem 268 (1993), pp. 6995-7010.

Brünger 1987- A. Brünger, Crystallographic $R$ factor refinement by molecular dynamics. Science 235 (1987), pp. 458-460.

Ellis et al. 1997 - P.J. Ellis, C.A. Appleby, J.M. Guss, W.N. Hunter, D.L. Ollis and H.C. Freeman, The crystal. structure of ferric soybean leghemoglobin $a$ nicotinate at $2.3 \AA$ resolution. Acta. Crystallog. sect. D (1997) in the press .

Fuchsman and Appleby 1979- W.H. Fuchsman and C.A. Appleby, $\mathrm{CO}$ and $\mathrm{O}_{2}$ complexes of soybean leghemoglobins: $\mathrm{pH}$ effects upon infrared and visible spectra. Comparisons with $\mathrm{CO}$ and $\mathrm{O}_{2}$ complexes of myoglobin and hemoblobin. Biochemistry 18 (1979), pp. 1309-1321.

Gibson et al. 1989 - Q.H. Gibson, J.B. Wittenberg, B.A. Wittenberg, D. Bogusz and C.A. Appleby, The kinetics of ligand 
binding to plant hemoglobins. J. Biol. Chem 264 (1989), pp. 100-107.

Hargrove and Olson 1996 - M.S. Hargrove and J.S. Olson, The stability of holomyoglobin is determined by heme affinity. Biochemistry 35 (1996), pp. 11310-11318.

Hargrove et al. 1994-M.S. Hargrove, E.W. Singleton, M.L. Quillin, L.A. Ortiz, G.N. Phillips, Jr, A.J. Mathews and J.S. Olson, His(E7)Tyr as a reagent for measurement of hemin loss. J. Biol. Chem 269 (1994), pp. 4207-4214.

Hargrove et al. 1996a - M.S. Hargrove, D. Barrick and J.S. Olson, The association rate constant for heme binding to globin is independent of protein structure. Biochemistry 35 (1996), pp. 11293-11299.

Hargrove et al. 1996b- M.S. Hargrove, A.J. Wilkinson and J.S. Olson, Structural. factors governing hemin dissociation from metmyoglobin. Biochemistry, 35 (1996), pp. 11300-11309.

Harutyunyan et al. 1995- E.H. Harutyunyan, T.N. Safonova, I.P. Kuranova, A.N. Popov, A.V. Teplyakov, G.V. Obmolova, A.A. Rusakov, B.K. Vainshtein, G.G. Dodson, J.C. Wilson and M.F. Perutz, The structure of deoxy- and oxy-leghaemoglobin from lupin. J. Mol. Biol251 (1995), pp. 104-115.

Hyldig-Nielsen et al. 1982 - J.J. Hyldig-Nielsen, E.O. Jensen, K. Paludan, O. Wiborg, R. Garret, P. Jorgensen and K.A. Marcker, The primary structures of two leghemoglobin genes from soybean. Nucl. Acids Res 10 (1982), pp. 689-695.

Ikeda-Saito et al. 1981 - M. Ikeda-Saito, H. Hori, T. Inubushi and T. Yonetani, Studies on cobalt myoglobins and hemoglobins. J. Biol. Chem 256 (1981), pp. 10267-10271.

Ji et al. 1994a- L. Ji, M. Becana, G. Sarath and R.V. Klucas, Cloning and sequence analysis of a cDNA encoding ferric leghemoglobin reductase from soybean nodules. Plant Physiol 104 (1994), pp. 453-459.

Ji et al. 1994b- L. Ji, M. Becana, G. Sarath, L. Shearman and R.V. Klucas, Over-expression in Escherichia coli and characterization of a soybean ferric leghemoglobin reductase. Plant Physiol 106 (1994), pp. 203-209.

Jun et al. $1994-$ H.-K. Jun, G. Sarath and F.W. Wagner, Detection and purification of modified leghemoglobins from soybean root nodules. Plant Sci 100 (1994), pp. 31-40.

Kloek et al. 1993 - A.P. Kloek, J. Yang, F.S. Mathews, C. Frieden and D.E. Goldberg, The tyrosine B10 hydroxyl is crucial. for oxygen avidity of Ascaris hemoglobin. J. Biol. Chem 269 (1993), pp. 2377-2379.

Kong et al. 1983 - S.B. Kong, J.D. Cutnell and G.N. La Mar, Proton nuclear magnetic resonance study of the dynamic stability of the heme pocket of soybean leghemoglobin $a$. J. Biol. Chem 258 (1983), pp. 3843-3849.

Kunkel 1985- T.A. Kunkel, Rapid and efficient site-specific mutagenesis without phenotypic selection. Proc. Natl Acad. Sci. USA 82 (1985), pp. 488-492.

Lee et al. 1993 - H.C. Lee, J.B. Wittenberg and J. Peisach, Role of hydrogen bonding to bound dioxygen in soybean leghemoglobin. Biochemistry 32 (1993), pp. 11500-11506.

Martin et al. 1990 - K.D. Martin, L. Saari, W. Guang-Xin, T. Wang, L.J. Parkhurst and R.V. Klucas, Kinetics and thermodynamics of oxygen, $\mathrm{CO}$, and azide binding by the subcomponents of soybean leghemoglobin. J. Biol. Chem 265 (1990), pp. 19588-19593.
Mathews et al. 1989 - A.J. Mathews, R.J. Rohlfs, J.S. Olson, J. Tame, J.P. Renaud and K. Nagai, The effects of E7 and E11 mutations on the kinetics of ligand binding to R state human hemoglobin. J. Biol. Chem 264 (1989), pp. 16573-16583.

Mathews et al. 1991 - A.J. Mathews, J.S. Olson, J.-P. Renaud, J. Tame and K. Nagai, The assignment of carbon monoxide association rate constants to the a and $\beta$ subunits in native and mutant human deoxyhemoglobin tetramers. J. Biol. Chem 266 (1991), pp. 21631-21693.

Mims et al. 1983 - M.P. Mims, A.G. Porras, J.S. Olson, R.W. Noble and J.A. Peterson, Ligand binding to heme proteins. J. Biol. Chem 258 (1983), pp. 14219-14232.

Moore and Gibson 1976 - E.G. Moore and Q.H. Gibson, Cooperativity in the dissociation of nitric oxide from hemoglobin. J. Biol. Chem 251 (1976), pp. 2788-2794.

Nagai et al. 1987 - K. Nagai, B. Luisi, D. Shih, G. Miyazaki, K. Imai, C. Poyart, A. De Young, L. Kwiatkowsky, R.W. Noble, S.-H. Lin and N.-T. Yu, Distal. residues in the oxygen binding site of haemoglobin studied by protein engineering. Nature 329 (1987), pp. 858-860.

Ollis et al. 1983-D.L. Ollis, C.A. Appleby, P.M. Colman, A.E. Cutten, J.M. Guss, M.P. Venkatappa and H.C. Freeman, Crystal. structure of soybean ferric leghaemoglobin $a$ nicotinate at a resolution of $3.3 \AA$ A. Aust. J. Chem 36 (1983), pp. $451-468$

Olson 1981 - J.S. Olson, Stopped-flow, rapid mixing measurements of ligand binding to hemoglobin and red cells. Methods Enzymol 76 (1981), pp. 631-652.

Olson and Phillips 1996 - J.S. Olson and G.N. Phillips, Jr, Kinetic pathways and barriers for ligand binding to myoglobin. J. Biol. Chem 271 (1996), pp. 17593-17596

Phillips et al. 1990 - G.N. Phillips, Jr, R.M. Arduini, B.A. Springer and S.G. Sligar, Crystal. structure of myoglobin from a synthetic gene. Proteins: Struct. Funct. Genet 7 (1990), pp. 358-365.

Quillin et al. 1993 - M.L. Quillin, R.M. Arduini, J.S. Olson and G.N. Phillips, Jr, High-resolution crystal. structures of distal. histidine mutants of sperm whale myoglobin. J. Mol. Biol 234 (1993), pp. 140-155.

Quillin et al. 1995 - M.L. Quillin, T. Li, J.S. Olson, G.N. Phillips, Jr, Y. Dou, M. Ikeda-Saito, R. Regan, M. Carlson, Q.H. Gibson, H. Li and R. Elber, Structural. and functional. effects of apolar mutations of the distal. valine in myoglobin. J. Mol. Biol 245 (1995), pp. 416-436.

Reisberg and Olson 1980 - P.I. Reisberg and J.S. Olson, Rates of isonitrile binding to the isolated $\alpha$ and $\beta$ subunits of human hemoglobin. J. Biol. Chem 255 (1980), pp. 4151-4158.

Rohlfs et al. 1988 - R.J. Rohlfs, J.S. Olson and Q.H. Gibson, A comparison of the geminate recombination kinetics of several. monomeric heme proteins. J. Biol. Chem 263 (1988), pp. 100-107.

Saari and Klucas 1984- L.L. Saari and R.V. Klucas, Ferric leghemoglobin reductase from soybean root nodules. Arch. Biochem. Biophys 231 (1984), pp. 102-113.

Sambrook et al. 1989 - J Sambrook, E.F. Fritsch and T. Maniatis. Molecular Cloning: A Laboratory Manual. (2nd edit. ed.),, Cold Spring Harbor Laboratory Press, Cold Spring Harbor, NY (1989). 
Springer and Sligar 1987 - B.A. Springer and S.G. Sligar, Highlevel expression of sperm whale myoglobin in Escherichia coli. Proc. Natl Acad. Sci. USA 84 (1987), pp. 8961-8965.

Springer et al. 1989- B.A. Springer, K.D. Egeberg, S.G. Sligar, R.J. Rohlfs, A.J. Mathews and J.S. Olson, Discrimination between oxygen and carbon monoxide and inhibition of autooxidation by myoglobin. J. Biol. Chem 264 (1989), pp. 3057-3060.

Springer et al. 1994 - B.A. Springer, S.G. Sligar, J.S. Olson and G.N. Phillips, Jr, Mechanisms of ligand recognition in myoglobin. Chem. Rev 94 (1994), pp. 699-714.

Stetzkowski et al. 1979 - F. Stetzkowski, R. Cassoly and R. Banerjee, Binding of alkylisocyanides with soybean leghemoglobin. J. Biol. Chem 254 (1979), pp. 11351-11356.
Stetzkowski et al. 1985- F. Stetzkowski, R. Banerjee, M.C. Marden, D.K. Beece, S.F. Bowne, W. Doster, L. Eisenstein, H. Frauenfelder, L. Reinisch, E. Shyamsunder and C. Jung, Dynamics of dioxygen and carbon monoxide binding to soybean leghemoglobin. J. Biol. Chem 260 (1985), pp. 8803-8809.

Vainshtein et al. 1975- B.K. Vainshtein, E.G. Arutyunyan, I.P. Kuranova, V.V. Borisov, N.I. Sosfenov, A.G. Pavlovskii, A.I. Grebenko and N.V. Konareva, X-ray study of leghemoglobin. I. Purification, crystallization, and preparation of derivatives containing heavy atoms. Sov. Phys. Crystallog 19 (1975), pp. 598-601. 